$21^{\text {st }}$ Annual International Symposium

October 23-25, 2018 | College Station, Texas

\title{
Numerical Modelling for Effect of Water Curtain in Mitigating Toxic Gas Release
}

\author{
Dong Seok Min, Eui-young Oh, Seungho Jung \\ Department of Environmental and safety Engineering, Ajou University \\ Suwon, Republic of Korea
}

E-mail: processsafety@ajou.ac.kr

\begin{abstract}
As the chemical industry has developed, the use of toxic substances has increased, and leakage accidents have increased. Among various substances, hydrogen fluoride (HF) and ammonia $\left(\mathrm{NH}_{3}\right)$ are representative materials for the study since both are hazardous and important in the chemical industry. HF is a strong, pervious substance that is a stimulates on the body, respiratory system, and skin. HF is widely used in electronics manufacturing as a polisher and disinfectant. Since an HF release accident occurred in Gumi, S. Korea (2012) the Korea Occupational Safety and Health Agency (KOSHA) has emphasized that special attention and management is needed with respect to this toxic substance. $\mathrm{NH}_{3}$ is widely used in the semiconductor industry and chemical processes. There have been about 20 large accidents regarding $\mathrm{NH}_{3}$ around the world in last 10 years.

In this study, ANSYS Fluent, a computational fluid dynamics (CFD) program, was used to identify the effect of a water curtain as a mitigation system for toxic substances that are leaked from industrial facilities. Simulations were conducted to analyze how effectively a water curtain mitigated the dispersion of toxic substances. To verify the accuracy of the simulation, Goldfish experiment and INERIS Ammonia dispersion experiment were simulated and compared. Various water curtains were applied to the simulated field experiment to confirm the mitigation factors of toxic substances. The results show that the simulations and experiments are consistent and that the dispersion of toxic substances can be mitigated by water curtains.
\end{abstract}




\section{Introduction}

As the chemical industry has developed, the use of toxic substances has increased, and leakage accidents have increased. Among various substances, $\mathrm{HF}$ and $\mathrm{NH}_{3}$ are representative materials for the study since both are hazardous and important in the chemical industry. HF is a strong, pervious substance that is a stimulates on the body, respiratory system, and skin. HF is widely used in electronics manufacturing as a polisher and disinfectant. Since an HF release accident occurred in Gumi, S. Korea (2012) the Korea Occupational Safety and Health Agency (KOSHA) has emphasized that special attention and management is needed with respect to this toxic substance. $\mathrm{NH}_{3}$ is widely used in the semiconductor industry and chemical processes. There have been about 20 large accidents regarding $\mathrm{NH}_{3}$ around the world in last 10 years [1-3].

In order to mitigate the impact from accidental releases of toxic chemicals, there are various systems equipped in the facilities such as dikes, secondary barriers, steam curtains, and water curtains. Among these, water spray system is known to effectively decrease the gas concentrations and prevent the movement of vapor cloud in the atmosphere after accidental toxic gas releases. To verify the effectiveness of water spray system, several researches have been undertaken with various field tests as well as Computational Fluid Dynamics (CFD). Dandrieux et al. (2001) verified the mitigation effect when using water curtains of the peacock tail type for $0.25 \mathrm{~kg} / \mathrm{s}$ release rate of ammonia gas. Bouet et al. (2005) did 15 times of field test with physical barriers and water curtains for ammonia as well. [4, 5]. Kim et al. (2012) experimented LNG dispersions with the full cone type water spray curtains and compared the concentrations near the release source with CFD dispersion simulations. Cheng et al. (2014) also did field test for ammonia to compare CFD simulation results with the experiments [6,7].

However, in these previous researches, the effectiveness to mitigate gas dispersions are significantly different for the peacock tail type. Dandrieux et al. (2001) showed very high mitigation efficiency in his experiment but there is almost no effect in the research of Bouet et al. (2005). It is mostly because;

1. Toxic gases were through water spray curtain area due to the high jet momentum.

2. Water spray curtain shape changed due to metrological conditions.

In this study, it is simulated to know the effectiveness of water spray curtains for accidental $\mathrm{HF}$ and $\mathrm{NH}_{3}$ release cases using ANSYS Fluent 18.0. Also we analyzed how the precious two researched have to be judged [8]. Simulations were conducted to analyze how effectively a water curtain mitigated the dispersion of toxic substances. To verify the accuracy of the simulation, Goldfish experiment and INERIS Ammonia dispersion experiment were simulated and compared. After validation with field experiments, in order to avoid the concentration change of atmospheric condition, the meteorological conditions were fixed concentration was compared with the presence or absence of the water spray curtain. Various water spray curtains were applied to the simulated field experiment to confirm the mitigation factors of toxic substances. The results show that the simulations and experiments are consistent and that the dispersion of toxic substances can be mitigated by water curtains $[9,10]$. 


\section{Numerical simulation}

ANSYS Fluent 18.0 is a program based on Navier-Stokes equations and capable of carrying out the physical modeling of fluid flow. In this study, we were to solve the relations of gas and water droplets so that we used Eulerian-Lagrangian method. We defined the problem as the steady state and solved it using Semi-Implicit Method for Pressure-Linked Equation method solver (SIMPLE).

\subsection{Gas flow modeling}

The governing equations are mass conservation, momentum conservation and energy conservation [11]. The equation for mass conservation can be written as follow;

$\frac{\partial \rho}{\partial \mathrm{t}}+\boldsymbol{\nabla} \cdot(\rho \mathbf{u})=0$

Where $\rho$ is the fluid density. Which can be expanded as follow;

$\frac{\partial u}{\partial x}+\frac{\partial v}{\partial y}+\frac{\partial w}{\partial z}=0$

The equations for momentum conservation can be written as follows;

$$
\begin{aligned}
& \frac{\partial(\rho u)}{\partial t}+\boldsymbol{\nabla} \cdot(\rho u \mathbf{u})=-\frac{\partial p}{\partial x}+\boldsymbol{\nabla} \cdot(\mu \boldsymbol{\nabla} u)+S_{M x} \\
& \frac{\partial(\rho v)}{\partial \mathrm{t}}+\boldsymbol{\nabla} \cdot(\rho v \mathbf{u})=-\frac{\partial p}{\partial y}+\boldsymbol{\nabla} \cdot(\mu \boldsymbol{\nabla} v)+S_{M y} \\
& \frac{\partial(\rho w)}{\partial t}+\boldsymbol{\nabla} \cdot(\rho w \mathbf{u})=-\frac{\partial p}{\partial z}+\boldsymbol{\nabla} \cdot(\mu \boldsymbol{\nabla} w)+S_{M z}
\end{aligned}
$$

The above equations are for the conservation of momentum for $\mathrm{x}, \mathrm{y}, \mathrm{z}$ axis. $\mu$ is the viscosity term and $S_{M x}, S_{M y}, S_{M z}$ are terms for volumetric influences. The equation for energy conservation is as follow;

$\frac{\partial(\rho i)}{\partial t}+\boldsymbol{\nabla} \cdot(\rho i \mathbf{u})=-p \boldsymbol{\nabla} \cdot \boldsymbol{u}+\boldsymbol{\nabla} \cdot(k \boldsymbol{\nabla} T)+\Phi+S_{i}$

\subsection{Atmospheric boundary condition}


For the atmospheric boundary condition, the wind power law relationship between the wind speeds at one height and those at another is written in eqns (7-10) which depend upon atmospheric stability [12].

$U(z)=U\left(z_{1}\right) \times\left(\frac{z}{z_{1}}\right)^{p}$

$k(z)=\frac{\left(U^{*}\right)^{2}}{\sqrt{C_{\mu}}}$

$\varepsilon(z)=\frac{\left(U^{*}\right)^{3}}{\kappa z_{1}}$

$U^{*}=\left(\frac{\kappa\left(U\left(z_{1}\right)\right)}{\ln \left(\frac{Z_{1}}{z_{o}}\right)}\right)$

Where $\mathrm{U}$ is the wind speed, $\mathrm{U}^{*}$ is sheared wind spend and $\kappa$ is von karman constant of which value is 0.4 set for this study. $z_{1}$ is the known wind speed at a reference height and $z_{o}$ is the surface roughness factor. We have used 0.1 as $z_{o}$ for the $C$ air stability class and 0.14 for the D air stability class as recommended by the EPA [13].

In this simulation, the realizable $k$ - $\varepsilon$ was employed for turbulence model. This model is the modified version of the standard $k$ - $\varepsilon$ turbulence model and improves to better predict the spreading rate of both planar and round jets. The standard turbulence model is based on separate transport equations for the turbulence kinetic energy $(k)$ and its dissipation rate. The realizable $k$ $\varepsilon$ model equations are described as follows [14]:

$$
\begin{aligned}
& \frac{\partial}{\partial t}(\rho k)+\frac{\partial}{\partial x_{j}}\left(\rho k U_{i}\right)=\frac{\partial}{\partial x_{j}}\left[\left(\mu+\frac{\mu_{t}}{\sigma_{k}}\right) \frac{\partial k}{\partial x_{j}}\right]+G_{k}+G_{b}-\rho \varepsilon-Y_{M}+S_{k} \\
& \frac{\partial}{\partial t}(\rho \varepsilon)+\frac{\partial}{\partial x_{j}}\left(\rho \varepsilon U_{i}\right) \\
& =\frac{\partial}{\partial x_{j}}\left[\left(\mu+\frac{\mu_{t}}{\sigma_{\varepsilon}}\right) \frac{\partial \varepsilon}{\partial x_{j}}\right]+\rho C_{1} S \varepsilon-\rho C_{2} \frac{\varepsilon^{2}}{k+\sqrt{v \varepsilon}}+C_{1 \varepsilon} \frac{\varepsilon}{k} C_{3 \varepsilon} G_{b}+S_{\varepsilon} \\
& C_{1}=\max \left[0.43, \frac{\eta}{\eta+5}\right], \eta=\mathrm{S} \frac{k}{\varepsilon}, S=\sqrt{2 S_{i j} S_{i j}}
\end{aligned}
$$

where $G_{k}$ and $G_{b}$ represent the generation of turbulence kinetic energy due to the mean velocity gradients and buoyancy, respectively; $Y_{M}$ represents the contribution of the fluctuating 
dilatation in compressible turbulence to the overall dissipation rate; $\mu$ is the molecular viscosity; $\mu_{t}$ is the turbulence viscosity; $C_{2}, C_{1 \varepsilon}$ are constants; $\sigma_{k}$ and $\sigma_{\varepsilon}$ are the turbulent Prandtl numbers for $k$ and $\varepsilon$, respectively. $S_{k}$ and $S_{\varepsilon}$ are the increasing rate by the source.

\subsection{Water spray curtain modeling}

The discrete phase model (DPM) was used to analyze the relationship between water spray curtain and toxic gas dispersions. DPM Eulerian-Lagrangian frameworks are the approach for CFD simulation of multiphase systems, and toxic gas (continuous phase) is solved by Eulerian method, and water droplet (discrete phase) is solved by Lagrangian. The equations for that are as follows in eqns (14-16);

$$
\begin{aligned}
& \frac{d \boldsymbol{u}_{\boldsymbol{p}}}{d t}=\frac{\boldsymbol{u}-\boldsymbol{u}_{\boldsymbol{p}}}{\tau_{r}}+\frac{\boldsymbol{g}\left(\rho_{p}-\rho\right)}{\rho_{p}}+\boldsymbol{F} \\
& \tau_{r}=\frac{\rho_{p} d_{p}^{2}}{18 \mu} \frac{24}{C_{d} \operatorname{Re}} \\
& \operatorname{Re} \equiv \frac{\rho d_{p}\left|\boldsymbol{u}_{\boldsymbol{p}}-\boldsymbol{u}\right|}{\mu}
\end{aligned}
$$

Where $\mathrm{u}$ is the fluid speed, $u_{p}$ is the particle speed, $\mu$ is the fluid viscosity, $\rho$ is fluid density $\rho_{p}$ is the particle density, and $d_{p}$ is the diameter of the particle.

The specification of water spray curtains were set based on INERIS tests performed in 2005. The peacock tail type has 1200 liter/min of water flowrate at 8 barg and the water droplet temperature is assumed to be the atmospheric temperature and the diameter of water droplets are calculated based on Britter's (2011) equation [16].

$d_{p m} \equiv W e_{C} \frac{\sigma}{\rho g u_{r e l}^{2}}$

$W e_{C}$ is Weber number and $\rho_{g}$ is the density of surround gas. $u_{r e l}$ is the relative speed between the water jet and gas, $d_{p m}$ is the average droplet diameter and $\sigma$ is surface tension of the droplets. The more detailed of water spay curtain is in Table 1. 
Table 1 Simulation specification of water spray curtain

\begin{tabular}{cc}
\hline \multicolumn{2}{c}{ DPM Input Data } \\
\hline Parameter & Input Data \\
\hline Injection type & Surface (semicircular ring) \\
Nozzle size $(\mathrm{mm})$ & Radius : 70, width : 10 \\
Water flow rate $(\mathrm{kg} / \mathrm{s})$ & 19.9013 \\
Droplet Diameter $(\mu \mathrm{m})$ & 935 \\
Initial Droplet Velocity $(\mathrm{m} / \mathrm{s})$ & 46 \\
\hline
\end{tabular}

\subsection{Actual field test used in validation}

We used Ammonia large scale atmospheric dispersion experiments at INERIS from 1996 to 1997 for comparison of actual experiment with $\mathrm{NH}_{3}$ and CFD simulation. Out of 15 total trials conducted in accordance with the size, height, direction of the leak and presence of protection devices, we have chosen $4^{\text {th }}$ test for the reference and $11^{\text {th }}$ test for two peacock tail type water sprays for comparing with the simulation. The two water sprays had been installed at 60 meters away from the source. In the experiment, compressed liquefied $\mathrm{NH}_{3}$ was discharged from the pipe at a height of $1 \mathrm{~m}$ from the ground and was vaporized and diffused. The concentrations of liquefied $\mathrm{NH}_{3}$ were measured by sensors installed at $20 \mathrm{~m}, 50 \mathrm{~m}, 100 \mathrm{~m}, 200,500 \mathrm{~m}$.

We have selected the Goldfish experiment conducted in 1986 in Frenchman, Nevada in the USA for the comparison of the actual experiment and the simulation was. In this experiment, which consists of three trials with different conditions as shown in Table 3, the compressed liquid $\mathrm{HF}$ was discharged through the pipe at a height of $1 \mathrm{~m}$ to the ground. The liquefied HF was vaporized and spread in the downwind direction in the form of steam clouds, and the concentrations were measured by sensors installed at $300 \mathrm{~m}, 1000 \mathrm{~m}$, and $3000 \mathrm{~m}$ from the leak source.

Table 2 Information of Ammonia large scale atmospheric dispersion experiment

\begin{tabular}{cccccc}
\hline No. & $\begin{array}{c}\text { Mass flow } \\
\text { rate }(\mathrm{kg} / \mathrm{s})\end{array}$ & $\begin{array}{c}\text { Wind speed } \\
\text { at } 7 \mathrm{~m}(\mathrm{~m} / \mathrm{s})\end{array}$ & Air stability & $\begin{array}{c}\text { Temperature } \\
\left({ }^{\circ} \mathrm{C}\right)\end{array}$ & $\begin{array}{c}\text { Relative } \\
\text { humidity }(\%)\end{array}$ \\
\hline 4 & 4.2 & 3 & $\mathrm{D}$ & 12.5 & 82 \\
11 & 3 & 5 & $\mathrm{C}$ & 24 & 24 \\
\hline
\end{tabular}

Table 3 Information of Gold fish experiment

\begin{tabular}{cccccc}
\hline No. & Mass flow & Wind speed & Air stability & Temperature & Relative \\
\hline
\end{tabular}




\begin{tabular}{cccccc}
\hline & rate $(\mathrm{kg} / \mathrm{s})$ & at $2 \mathrm{~m}(\mathrm{~m} / \mathrm{s})$ & & $\left({ }^{\circ} \mathrm{C}\right)$ & humidity $(\%)$ \\
\hline 1 & 27.67 & 5.6 & $\mathrm{D}$ & 37.1 & 4.9 \\
2 & 10.46 & 4.2 & $\mathrm{D}$ & 36.1 & 10.7 \\
3 & 10.27 & 5.4 & $\mathrm{D}$ & 34.1 & 17.7 \\
\hline
\end{tabular}

\subsection{Simulation specification}

For all comparisons, we unified the atmospheric conditions in order to minimize the variables. Actually, the temperature was about 5 to $24^{\circ} \mathrm{C}$ and the humidity was about 20 to $90 \%$ in the $\mathrm{NH}_{3}$ field test. In the HF test, the experiment was conducted in a little bit higher temperatures and lower humidity. Since the tendency of gas diffusion differs greatly according to temperature and humidity, it was fixed at $25^{\circ} \mathrm{C}$ and $50 \%$. In the $\mathrm{NH}_{3}$ and $\mathrm{HF}$ field tests, the different parts of the wind speed and reference height were set at $10 \mathrm{~m}$ height to $3 \mathrm{~m} / \mathrm{s}$ and the atmospheric stability was applied to D class.

The following scenarios were set up to compare the effect of water spray curtain reduction on $\mathrm{NH}_{3}$ leaks. First, in the INERIS field test, two water spray curtains were installed $6.5 \mathrm{~m}$ apart from the center line, but in this study, it was installed in the center line so that the toxic gas could contact the water spray curtain as much as possible. Based on this, we set up three different scenarios as follows;

1. Installed at $30 \mathrm{~m}$ and $60 \mathrm{~m}$ from the source simultaneously

2. Installed at $30 \mathrm{~m}$

3. Installed at $60 \mathrm{~m}$

In order to confirm the difference in efficiency of water spray curtain in existing field tests, we conducted the experiments with Dandrieux et al. (2001) at $0.15 \mathrm{~m}$ height, $0.25 \mathrm{~kg} / \mathrm{s}$ mass flow rate and $5 \mathrm{~m}$ water spray curtain based on the test, we added a small scale simulation (W5). In $\mathrm{HF}$, the leakage source and leakage were kept the same as the field test, and the other conditions were set the same as the ammonia large scale simulation.

ANSYS Design Modeler 18.0 was employed to generate the geometry for atmospheric diffusion modeling. The size of the external flow region is $\mathrm{W} \times \mathrm{D} \times \mathrm{H}=580 \times 80 \times 40 \mathrm{~m} 3$ in the large scale simulation, width $(\mathrm{W}) \times$ depth $(\mathrm{D}) \times$ height $(\mathrm{H})=850 \times 100 \times 50 \mathrm{~m} 3$ in the validation case, In the small scale simulation, $\mathrm{W} \times \mathrm{D} \times \mathrm{H}=100 \times 40 \times 20 \mathrm{~m} 3$. As shown in Figure 1, the boundary conditions are the velocity inlet at the air inlet, the side and top, respectively, and the outflow boundary conditions at the outlet. The ground are set to be the wall boundary condition and the mass flow inlet is applied to the horizontal leakage source.

The mesh generation was performed by a polyhedral mesh using a meshing program and fluent meshing provided by ANSYS. A polyhedral lattice refers to a lattice created by dividing a flow region into polyhedral. The polyhedral grating can shorten the analysis time compared to the existing tetrahedral or hexahedral meshes, and can be produced with equal or better accuracy, and the grating generation time can also be shortened [17]. 


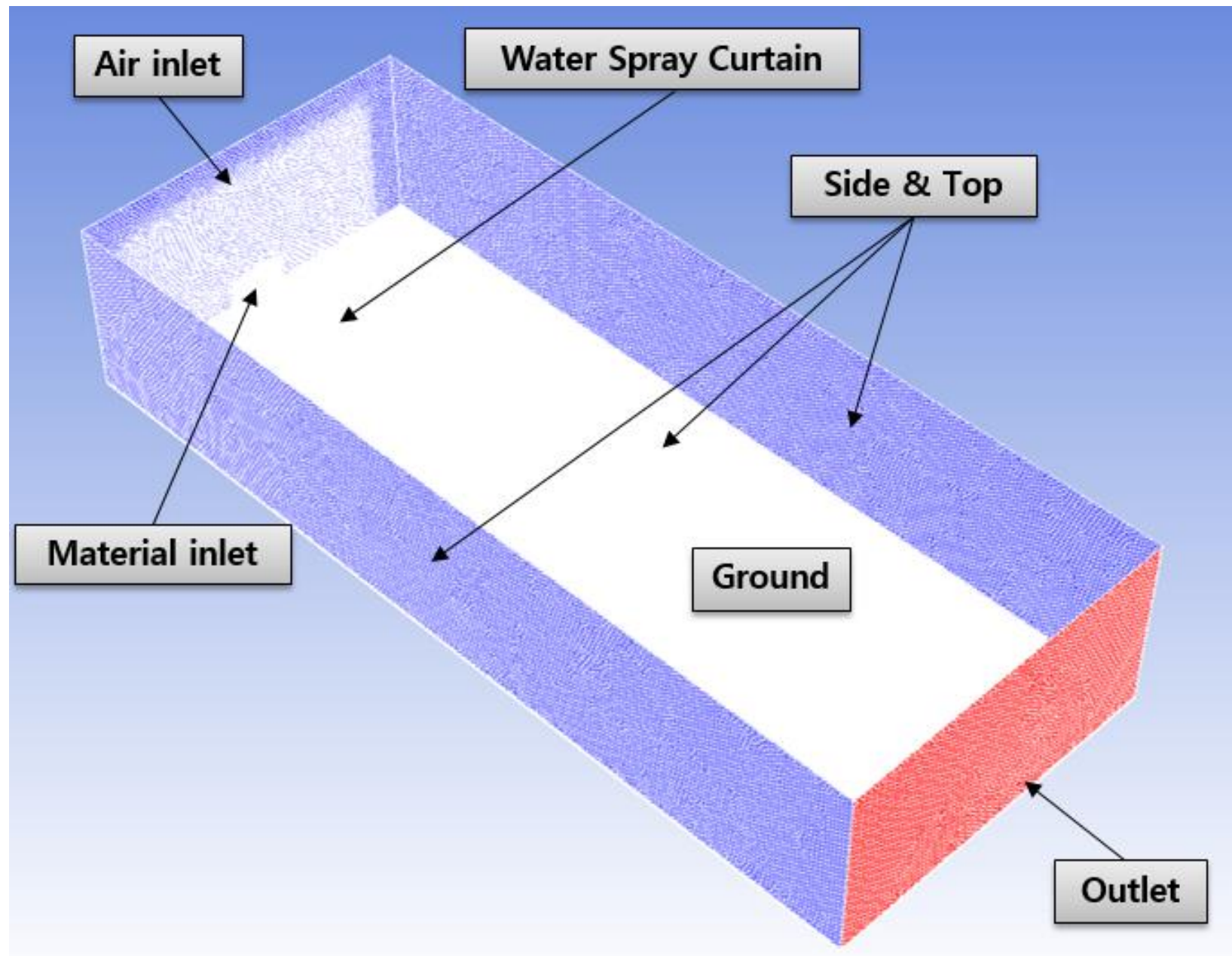

Figure 1. 3D Geometry and boundary condition of small scale simulation 


\section{Results}

\subsection{Comparison with field experiment}

\subsubsection{Comparison with ammonia field experiment}

The results both of the field test for ammonia leaks and the simulation results are shown in Table 4. From the comparison of the concentrations for 6 locations at $1 \mathrm{~m}$ height, the differences between the reference (test \# 4) and the simulation were between $71 \%$ and $117 \%$. The difference of concentration was about $30 \%$ at the nearest $(20 \mathrm{~m})$ of the measurement points and within $20 \%$ at $50 \mathrm{~m}$ and $800 \mathrm{~m}$. The difference between test \#11 with the water spray curtain and the simulation occurred from as little as $68 \%$ to as much as $200 \%$.

The comparison also showed that the difference in concentration was about $30 \%$ compared to the experiment at $20 \mathrm{~m}$ and within $10 \%$ of the experimental data up to $500 \mathrm{~m}$. However, at $800 \mathrm{~m}$, the concentration difference of the experimental versus simulation suddenly rose to $100 \%$. Therefore, it was concluded that the efficiency of water spray curtain was effective up to $500 \mathrm{~m}$ in large scale simulation. Based on this, the analysis domain was defined.

Table 4 Comparison with field test and simulation for $\mathrm{NH}_{3}$

\begin{tabular}{|c|c|c|c|c|c|c|}
\hline \multirow{2}{*}{$\begin{array}{l}\text { Downwin } \\
\text { d Distance } \\
(\mathrm{m})\end{array}$} & \multicolumn{3}{|c|}{ Test No. 4} & \multicolumn{3}{|c|}{ Test No. 11} \\
\hline & $\begin{array}{c}\text { Experime } \\
\text { nt } \\
(\mathrm{ppm})\end{array}$ & $\begin{array}{l}\text { Simula } \\
\text { tion } \\
(\mathrm{ppm})\end{array}$ & $\begin{array}{l}\text { Ratio } \\
\text { (Sim./E } \\
\text { xp.) }\end{array}$ & $\begin{array}{l}\text { Experi } \\
\text { ment } \\
(\mathrm{ppm})\end{array}$ & $\begin{array}{l}\text { Simula } \\
\text { tion } \\
(\mathrm{ppm})\end{array}$ & $\begin{array}{l}\text { Ratio } \\
\text { (Sim./E } \\
\text { xp.) }\end{array}$ \\
\hline 20 & 65000 & 46000 & 0.71 & 65000 & 44000 & 0.68 \\
\hline 50 & 27000 & 27000 & 1.00 & 27000 & 25000 & 0.93 \\
\hline 100 & 16000 & 17000 & 1.06 & 15000 & 13000 & 0.87 \\
\hline 200 & 10000 & 8900 & 0.89 & 3500 & 3700 & 1.06 \\
\hline 500 & 1200 & 1400 & 1.17 & 300 & 280 & 0.93 \\
\hline 800 & 500 & 500 & 1.00 & 80 & 160 & 2.00 \\
\hline
\end{tabular}

\subsubsection{Comparison with hydrogen fluoride field experiment}

Table 5 shows the comparison of simulation data with test \#1 of Goldfish (HF leak) field test. Simulation results ranging from $300 \mathrm{~m}$ to $3000 \mathrm{~m}$ showed similar trends to field tests, which is generally low in simulation results. Simulation results show that the concentration of $52 \%$ compared to the experiment at a distance of $300 \mathrm{~m}$ from the source of leakage, the concentration of $59 \%$ compared to the experiment at $1000 \mathrm{~m}$, and the concentration of $56 \%$ compared to the experiment at $3000 \mathrm{~m}$. Based on this, the model used for comparison with the water spray curtain field test results of ammonia was applied to HF as well. 
Table 5 Comparison with field test and simulation for HF

\begin{tabular}{cccc}
\hline $\begin{array}{c}\text { Downwin } \\
\mathrm{d} \text { Distance } \\
(\mathrm{m})\end{array}$ & & Test No. 1 & \\
\hline & $\begin{array}{c}\text { Experiment } \\
(\mathrm{ppm})\end{array}$ & $\begin{array}{c}\text { Simulatio } \\
\mathrm{n} \\
(\mathrm{ppm})\end{array}$ & $\begin{array}{c}\text { Ratio } \\
(\text { Sim./Exp.) }\end{array}$ \\
\hline 300 & 25473 & 13273 & 0.52 \\
1000 & 3098 & 1842 & 0.59 \\
3000 & 411 & 232 & 0.56 \\
\hline
\end{tabular}

\subsection{Mitigation efficiency of water spray curtain}

The reduction effect of water spray curtain was investigated after verifying the simulation of $\mathrm{NH}_{3}$ and $\mathrm{HF}$ with actual experiments. The reduction efficiency of the water spray curtain was calculated as shown in equation (18).

Efficiency $=1-\frac{C_{w}}{C_{N o} \text {. }}$

$C_{W}$. Is the concentration when water spray curtain is used and $C_{N o W}$. is the concentration when water spray curtain is not used. In the large scale simulation of $\mathrm{NH}_{3}$, the concentration was measured at a height of $1 \mathrm{~m}$ from the ground. As a result, the reduction effect was observed at a distance of $100 \mathrm{~m}$ or less from the water spray curtain as shown in figure 2 . However, as the measurement distance increases, the efficiency gradually decreases. When the distance reaches a certain distance, the efficiency becomes negative. Efficiency increases again after a certain distance. This is the same trend as the result of the INERIS ammonia leak field test.

In the large scale simulation of $\mathrm{NH}_{3}$ of which concentrations were measured at a height of $1 \mathrm{~m}$ from the ground, the reduction effect was observed at $100 \mathrm{~m}$ or less from the water spray curtain as shown in Figure 2. However, as the measurement distance increases, the efficiency gradually decreases. When the distance reaches a certain distance, the efficiency becomes negative. The efficiency increases again after a certain distance, which showed the same trend as the INERIS ammonia leakage field test.

The efficiency of the water spray curtain installed only at $60 \mathrm{~m}$ was slightly higher when the water spray curtain was installed only at $30 \mathrm{~m}$ behind the leak source. Nevertheless, the overall reduction effect of toxic gases by water spray curtains was less than $20 \%$. However, when the water spray curtain was installed both at $30 \mathrm{~m}$ and $60 \mathrm{~m}$ simultaneously, the efficiency becomes a bit better. Section where the reduction efficiency became negative is reduced.

The large scale simulation results of HF showed that the reduction effect did not occur near the water spray curtain as shown in figure 3, but the effect was increased as the distance 
increased. The efficiency was less than $10 \%$ within $100 \mathrm{~m}$ from the leak source, but it increased gradually to approximately $30 \%$ at $500 \mathrm{~m}$.

The efficiency of water spray curtain only at $30 \mathrm{~m}$ was higher than that of water spray curtain only at $60 \mathrm{~m}$. The water spray curtains installed both at $30 \mathrm{~m}$ and $60 \mathrm{~m}$ were not significantly different from the water spray curtain installed only at $30 \mathrm{~m}$.

In the small scale simulation of $\mathrm{NH}_{3}$, the results of measured concentration for the height from $15 \mathrm{~cm}$ to $100 \mathrm{~m}$ are shown in figure 4 and Figure 5. Although a certain tendency was not found, the reduction efficiency was about $40 \sim 50 \%$ after $20 \mathrm{~m}$ of distance. This is much higher reduction efficiency compared to the large simulations. The efficiency of the small-scale simulation of $\mathrm{NH}_{3}$ was more than twice to the large-scale simulation in the entire distances.

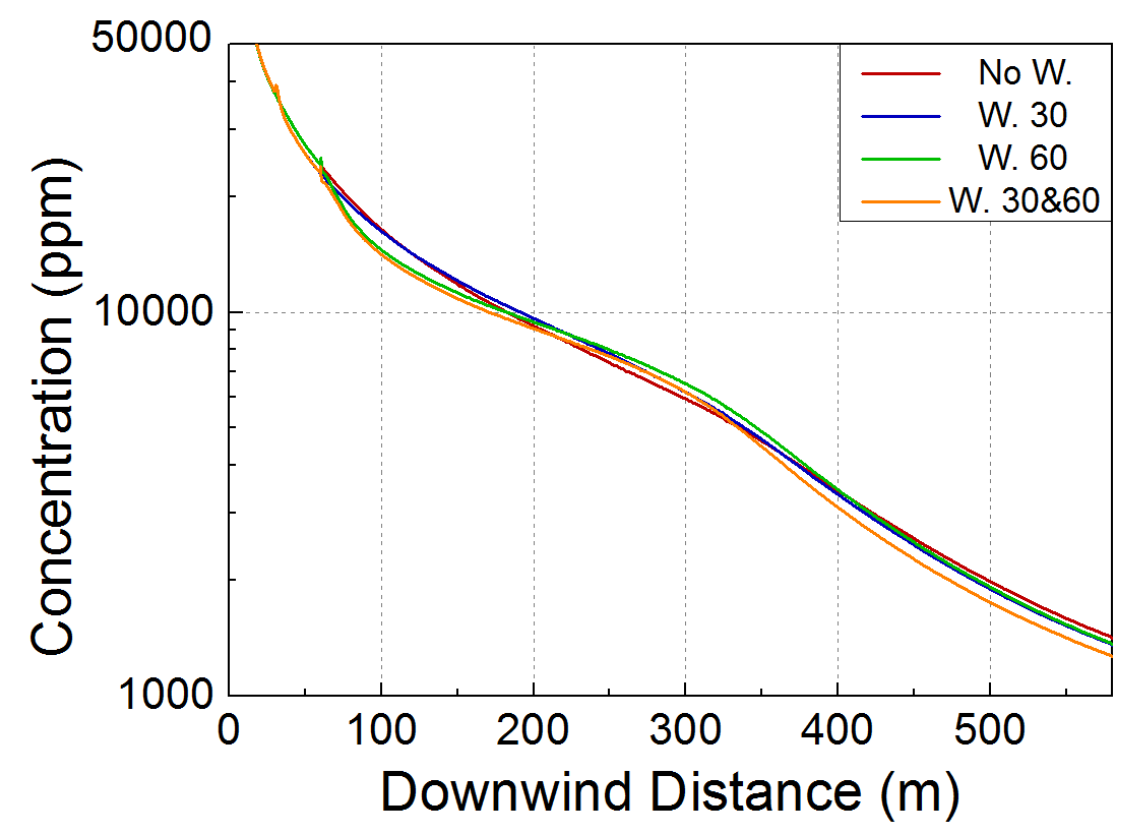

Figure 2. Variation of $\mathrm{NH}_{3}$ concentration according to downwind distance by water spray curtain at large scale simulation 


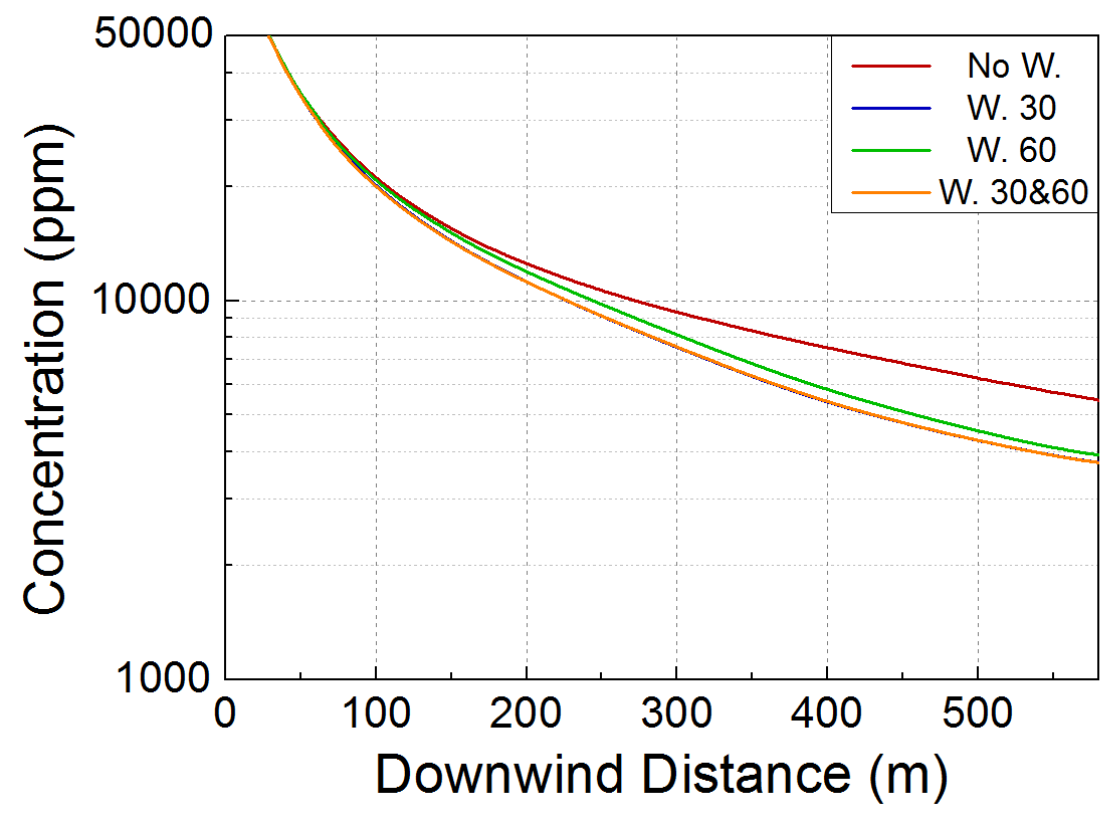

Figure 3. Variation of HF concentration according to downwind distance by water spray curtain at large scale simulation

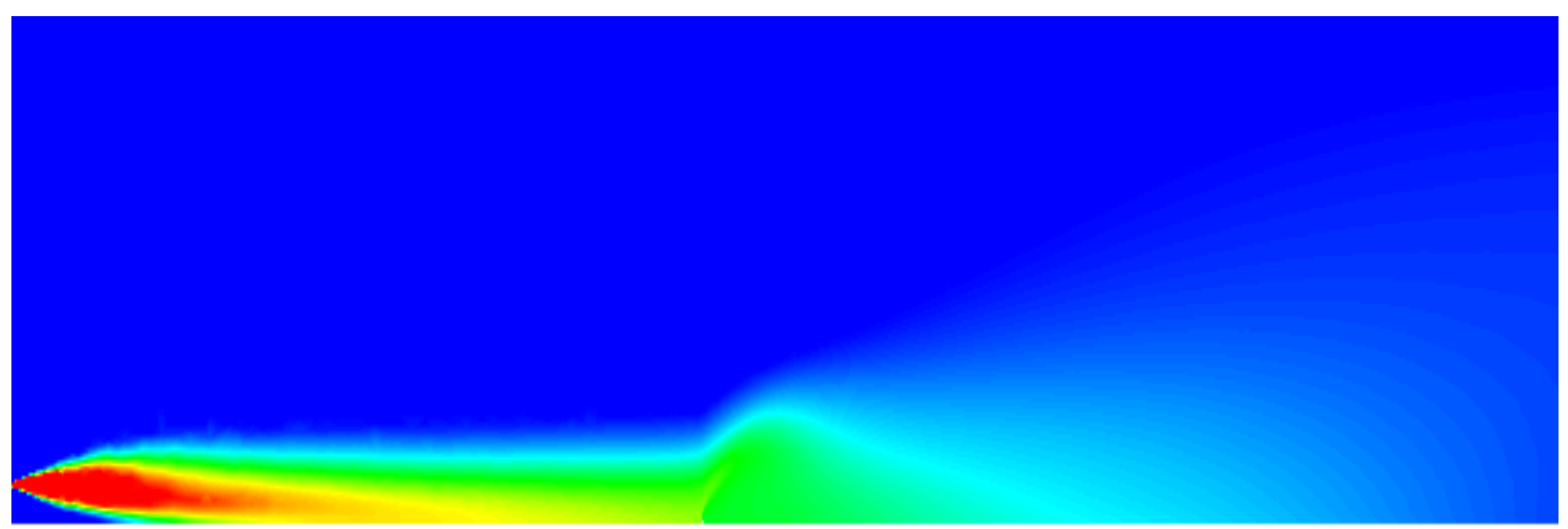

contous.1

Mole fraction of nh3

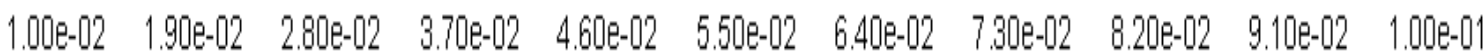

Figure 5. Mitigation effect contour of $\mathrm{NH}_{3}$ concentration according to downwind distance by water spray curtain at 5 m 


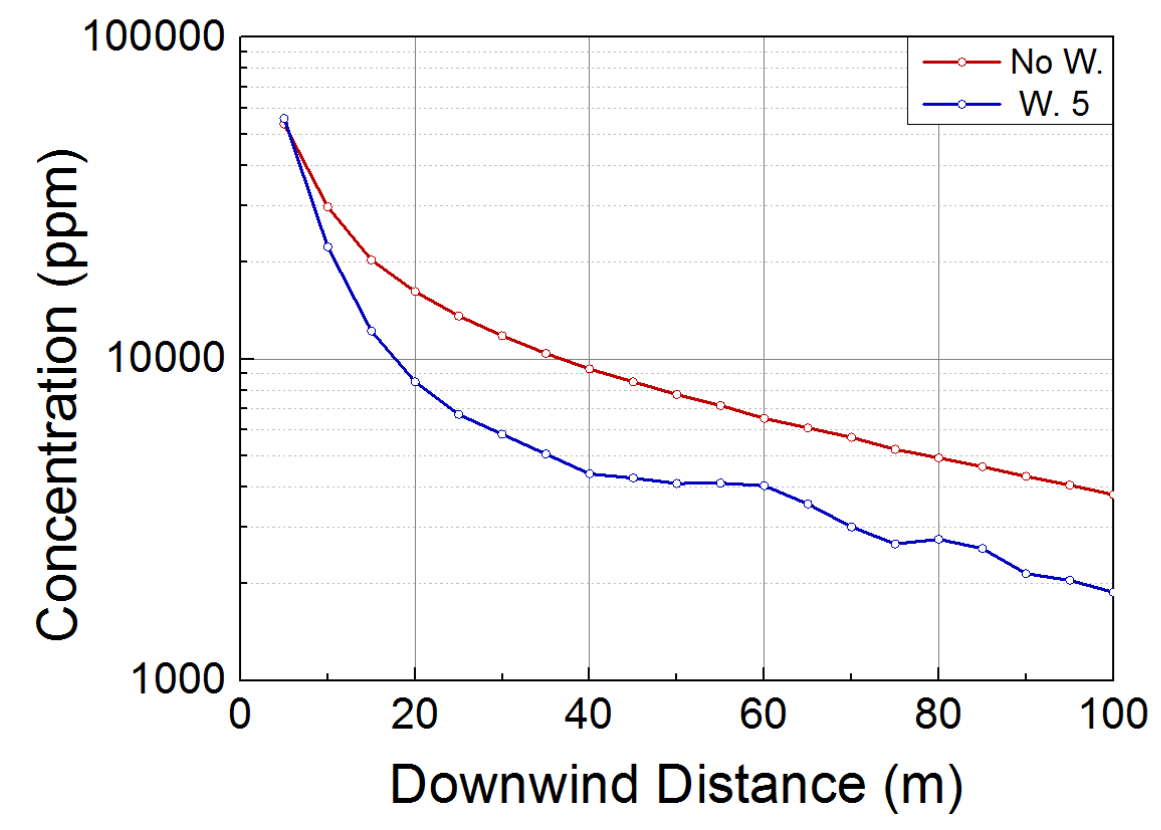

Figure 5. Variation of $\mathrm{NH}_{3}$ concentration according to downwind distance by water spray curtain at small scale simulation

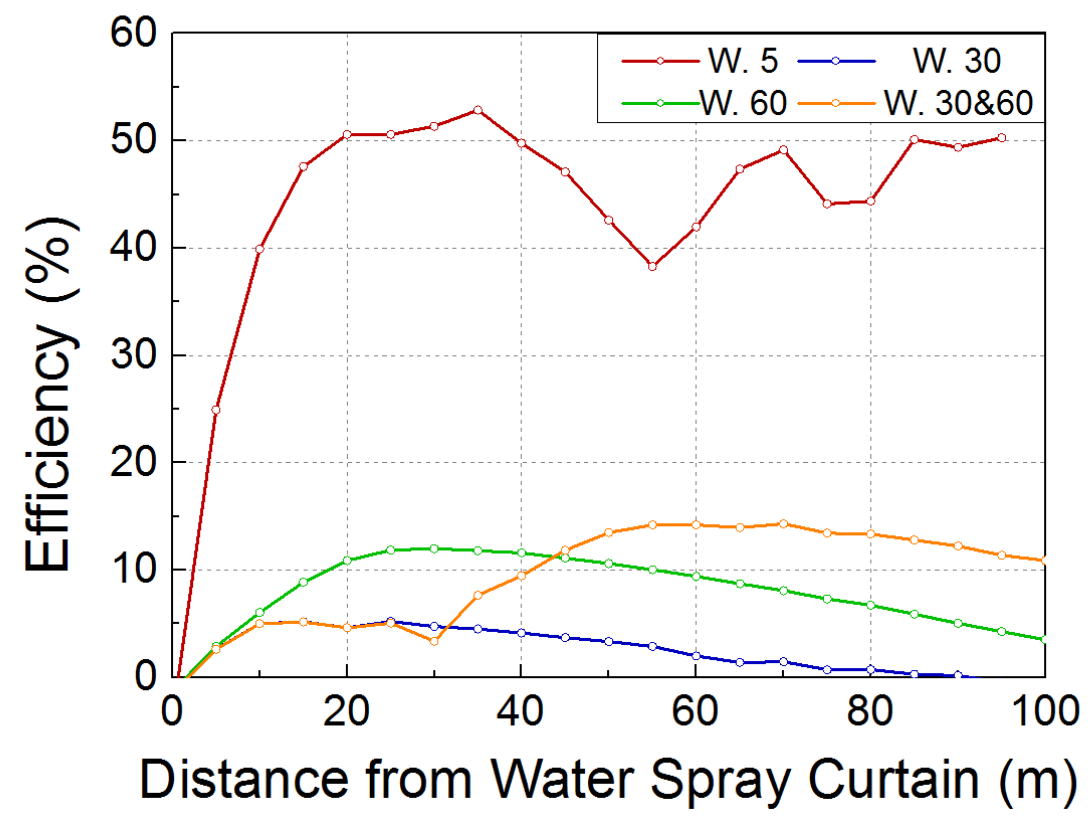

Figure 6. Efficiency water spray curtain according to distance from installation location at small scale simulation and large scale simulation 


\section{Conclusion}

In this study, the effects of $\mathrm{NH}_{3}$ and $\mathrm{HF}$ leakages with the peacock tail type water spray curtain were verified by simulations using computational fluid dynamics. We found the following results by analyzing the reduction efficiency of water spray curtain through the large scale simulation of $\mathrm{NH}_{3}$ and $\mathrm{HF}$ and the small scale simulation of $\mathrm{NH}_{3}$.

First, the efficiency difference of the water spray curtain of ammonia occurred according to the position of the leakage source. The closer to the point where the gas release source is from the water curtain, the more the concentration of the toxic material vapor is reduced by the physical effect.

The difference in the effect of water spray curtain according to the type of material was also confirmed. In the large scale simulation, the water spray for $\mathrm{NH}_{3}$ shows good efficiency at a short distance and then declines with the distance. On the other hand, the efficiency for HF tended to increase with distance from water spray curtain in large scale simulation. The reason for this difference is thought to be the density difference of the material. Because of the low boiling point and the high molecular weight of $\mathrm{NH}_{3}$ in the leaking state at the boiling point of the material, $\mathrm{NH}_{3}$ with a high density was relatively less affected by the water spray curtain.

These results show that different applications of the water spray curtain are required depending on the type of material and the leakage distance. In this simulation, when the water spray curtain was applied to the $\mathrm{NH}_{3}$ release, the reduction efficiency occurred at the relatively far distances over $400 \mathrm{~m}$. Therefore, in this case, it is necessary to install the water spray curtain in a proper position in order to check the efficiency of the water spray curtain.

One of the applications is to install water spray curtains on the dike or physical barriers installed around the hazardous chemical storage facilities. In the case of water-reactive chemical or water-prohibiting substance, it should not be applied. This study would help how to install the water spray curtain in the optimal place depending on materials and situations in case of hazardous chemical accidents. 


\section{References}

1. Bae, C.A., Chung, S.T., A study on Awareness of Risks and Countermeasures for Chemical Accidents among Residents near Chemical Plants. Crisisonomy, 2017. 13(5): p. 123-134.

2. Anjana, N.S., Amarnath, A., Harindranathan Nair, M.V., Toxic hazards of ammonia release and population vulnerability assessment using geographical information system. Journal of Environmental Management, 2018. 210: p. 201-209.

3. Yang, S., Jeon, K., Kang, D., Han, C., Accident analysis of the Gumi hydrogen fluoride gas leak using CFD and comparison with post-accidental environmental impacts. Journal of Loss Prevention in the Process Industries, 2017. 210: p. 207-215.

4. Dandrieux, A., Dusserre, G., Ollivier, J., Fournet, H., Effectiveness of water curtains to protect firemen in case of an accidental release of ammonia: comparison of the effectiveness for two different release rates of ammonia. Journal of Loss Prevention in the Process Industries, 2001. 14: p. 349-355.

5. Bouet, R., Dupletuer, S., Salvi, O., Ammonia large scale atmospheric dispersion experiments in industrial configurations. Journal of Loss Prevention in the Process Industries, 2005. 18: p. 512-519.

6. Kim, B.K., Ng, D., Mentzer, R.A., Mannan, M.S., Modeling of Water-Spray Application in the Forced Dispersion of LNG Vapor Cloud Using a Combined Eulerian-Lagrangian Approach. Ind. Eng. Chem. Res., 2012. 51: p. 13803-13814.

7. Cheng, C., Tan, W., Liu, L., Numerical simulation of water curtain application for ammonia release dispersion. Journal of Loss Prevention in the Process Industries, 2014. 30: p. 105-112.

8. Chung, T.J., Computational Fluid Dynamics, 2002.

9. Goldwire, H.C., McRae, T.G., Johnson, G.W., Hipple, D.L., Koopman, R.P., McClure, J.W., Morris, L.K., Cederwall, R.T., Desert Tortoise series data report: 1983 pressurized ammonia spills, UCID-20562. Lawrence Livermore National Laboratory, 1985. Livermore, CA.

10. Blewitt, D.N., Yohn, J.F., Ermak, D.L., An evaluation of SLAB and DEGADIS heavy gas dispersion models using the HF spill test data. Proc. Int. Conf. on Vapor Cloud Modeling, 1987. AIChE, New York. p. 56-80.

11. Versteeg, V.K., Malalasekera, W., An Introduction to Fluid Dynamics. 1999. $2^{\text {nd }}$ edition.

12. Blocken, B., Stathopoulos, T., Carmeliet, J., CFD simulation of the atmospheric boundary layer :- wall function problems. Atmospheric Environment, 2007. 41(2): p. 238-252.

13. EPA, RMP consequence analysis guidance. 1996. 
14. Shih, T.H., Liou, W.W., Shabbir, A., Yang, Z., Zhu, J., A New k - $\varepsilon$ Eddy-Viscosity Model for High Reynolds Number Turbulent Flows - Model Development and Validation. Computers Fluids, 1995.24(3): p. 227-238.

15. Gosman, A.D., Ioannides, E., Aspects of computer simulation of liquid-fuelled combustors. J. Energy, 1983. 7(6): p. 482-490.

16. Britter, R., Weil, J., Leung, J., Hanna, S., Toxic industrial chemical (TIC) source emissions modeling for pressurized liquefied gases. Atmospheric Environment, 2011. 45: p. 1-25.

17. Symscape, Polyhedral, Tetrahedral, and Hexahedral Mesh Comparison. 2013. https://www.symscape.com/polyhedral-tetrahedral-hexahedral-mesh-comparison. 